Muscle metabolism from near infrared spectroscopy during rhythmic handgrip in humans

Boushel, Robert Christopher; Pott, F; Madsen, P; Rådegran, G; Lonsdale, Markus Nowak; Quistorff, B; Secher, N

Published in:

European Journal of Applied Physiology

Publication date:

1998

Document version

Publisher's PDF, also known as Version of record

Citation for published version (APA):

Boushel, R. C., Pott, F., Madsen, P., Rådegran, G., Lonsdale, M. N., Quistorff, B., \& Secher, N. (1998). Muscle metabolism from near infrared spectroscopy during rhythmic handgrip in humans. European Journal of Applied Physiology, 79(1), 41-48. 
Robert Boushel · Frank Pott · Per Madsen

Göran Rådegran · Markus Nowak

Bjørn Quistorff · Niels Secher

\section{Muscle metabolism from near infrared spectroscopy during rhythmic handgrip in humans}

Accepted: 11 August 1998

\begin{abstract}
The rate of metabolism in forearm flexor muscles $\left(\mathrm{MO}_{2}\right)$ was derived from near-infrared spectroscopy $\left(\mathrm{NIRS}-\mathrm{O}_{2}\right.$ ) during ischaemia at rest rhythmic handgrip at $15 \%$ and $30 \%$ of maximal voluntary contraction (MVC), post-exercise muscle ischaemia (PEMI), and recovery in seven subjects. The $\mathrm{MO}_{2}$ was compared with forearm oxygen uptake $\left(\dot{V} \mathrm{O}_{2}\right)$ [flow $\times$ (oxygen saturation in arnterial blood-oxygen saturation in venous blood, $\left.S_{\mathrm{a}} \mathrm{O}_{2}-S_{\mathrm{v}} \mathrm{O}_{2}\right)$ ], and with the ${ }^{31} \mathrm{P}$-magnetic resonance spectroscopy-determined ratio of inorganic phosphate to phosphocreatine $\left(\mathrm{P}_{\mathrm{I}}: \mathrm{PCr}\right)$. During ischaemia at rest, the fall in NIRS- $\mathrm{O}_{2}$ was more pronounced [76 (SEM 3) to 3 (SEM 1)\%] than in $S_{\mathrm{v}} \mathrm{O}_{2}[71$ (SEM 3) to 59 (SEM 2)\%]. During the handgrip, NIRS$\mathrm{O}_{2}$ was lower at $30 \%$ compared to $15 \%$ MVC [58 (SEM 3) vs 67 (SEM 3)\%] while the $S_{\mathrm{v}} \mathrm{O}_{2}$ was similar [29 (SEM 3) vs 31 (SEM 4)\%]. Accordingly, $\mathrm{MO}_{2}$ as well as $\mathrm{P}_{\mathrm{I}}: \mathrm{PCr}$ increased twofold, while $\dot{V} \mathrm{O}_{2}$ increased only $30 \%$. During PEMI after $15 \%$ and $30 \%$ MVC, NIRS-O $\mathrm{O}_{2}$ fell to 9 (SEM 1)\% and " 0 ", but the use of oxygen by forearm muscles was not reflected in $S_{\mathrm{v}} \mathrm{O}_{2}$. During reperfusion after PEMI, the peak $\mathrm{NIRS}_{2} \mathrm{O}_{2}$ was lowest after intense exercise, while for $S_{\mathrm{v}} \mathrm{O}_{2}$ the reverse was seen. The discrepancies between NIRS-O ${ }_{2}$ and $S_{\mathrm{v}} \mathrm{O}_{2}$, and therefore between the estimates of the metabolic rate, would suggest significant limitations in sampling venous blood which is representative of the flexor muscle cap-
\end{abstract}

R. Boushel $(\bowtie) \cdot F$. Pott · G. Rådegran · M. Nowak The Copenhagen Muscle Research Centre, Rigshospitalet 2041,

University of Copenhagen,

Blegdamsvej 9, DK-2100 Copenhagen Ø, Denmark

P. Madsen · N.H. Secher

Department of Anaesthesia, Rigshospitalet,

University of Copenhagen,

Copenhagen, Denmark

B. Quistorff

Department of Medical Biochemistry and Genetics,

The Panum Institute, University of Copenhagen,

Copenhagen, Denmark illaries. In support of this contention, $S_{\mathrm{v}} \mathrm{O}_{2}$ and venous $\mathrm{pH}$ decreased during the first seconds of reperfusion after PEMI. To conclude, NIRS- $\mathrm{O}_{2}$ of forearm flexor muscles closely reflected the exercise intensity and the metabolic rate determined by magnetic resonance spectroscopy but not that rate derived from flow and the arterio-venous oxygen difference.

Key words Exercise $\cdot$ Energy production $\cdot$ Magnetic resonance spectroscopy $\cdot$ Venous oxygen saturation

\section{Introduction}

The signal obtained by near infrared spectroscopy of skeletal muscle (NIRS-O $\mathrm{O}_{2}$ ) has been assumed to reflect the combined absorption of light by haemoglobin $(\mathrm{Hb})$ and myoglobin $(\mathrm{Mb})$ depending upon their state of oxygenation, thereby representing the balance between the oxygen supply and consumption (Chance et al. 1988; 1992). Oxygen saturation in venous blood $\left(S_{\mathrm{v}} \mathrm{O}_{2}\right)$ was also been regarded as a reflection of this balance (Severinghaus 1994) and a relationship between these two variables is likely. During rhythmic handgrip Mancini et al. (1994) have reported such a correlation and Wilson et al. (1989) have found a similar relationship during electrical stimulation of muscles in the dog. Costes et al. (1996) have confirmed the correlation between NIRS-O and $S_{\mathrm{v}} \mathrm{O}_{2}$ during cycling in conditions of hypoxia, but a significant correlation was not found in normoxia. During cycling, NIRS- $\mathrm{O}_{2}$ of the quadriceps muscles has been shown to decrease with exercise intensity to reach a plateau at maximal intensity which was not exceeded by cuff-induced ischaemia, indicating complete desaturation (Chance et al. 1992). It has been suggested that changes in oxyhaemoglobin $\left(\mathrm{HbO}_{2}\right)$ may be more pronounced than in oxymyoglobin $\left(\mathrm{MbO}_{2}\right)$ (Richardson et al. 1995) except during complete anoxia or ischaemia (Wang et al. 1990). Interpretation of $S_{\mathrm{v}} \mathrm{O}_{2}$ measurements for comparison with NIRS-O ${ }_{2}$ is contingent upon obtaining blood samples which are representative of the capillaries and this 
has been shown to be especially uncertain during ischaemia (Deblasi et al. 1992).

The purpose of this study was to compare values of muscle oxygen saturation and consumption derived from measurements of NIRS, $S_{\mathrm{v}} \mathrm{O}_{2}$ with blood flow, and ${ }^{31} \mathrm{P}$ magnetic resonance spectroscopy $\left({ }^{31} \mathrm{P}-\mathrm{MRS}\right)$. Values were compared during ischaemia at rest, rhythmic handgrip, post-exercise muscle ischaemia (PEMI), and recovery. To assess if venous blood was representative of the capillary blood, care was taken to obtain samples immediately after flow was re-established during reperfusion of the forearm following release of an occlusion cuff on the upper arm. We hypothesized that the indices of the muscle metabolism would reflect the exercise intensity and determinations were made both at a moderate and a maximal intensity.

\section{Methods}

After informed consent, two healthy female and five healthy male subjects, aged $25-39$ years, participated in the study as approved by the Ethics Committee of Copenhagen. For the measurements of ischaemia at rest, each subjects was supine with the arm parallel to the body and the wrist in a neutral position. A cuff placed around the upper arm was inflated to $280 \mathrm{mmHg}$ and maintained at that pressure for $10 \mathrm{~min}$, while NIRS-O $\mathrm{O}_{2}$ and $S_{\mathrm{v}} \mathrm{O}_{2}$ were determined every minute. The cuff was then deflated and determinations were made immediately and every $5 \mathrm{~s}$ for the $1 \mathrm{st}$ min. Parallel experiments were conducted for ${ }^{31} \mathrm{P}-\mathrm{MRS}$ on a separate day, and venous blood was also sampled to determine the reproducibility of the responses between the test days. The ${ }^{31} \mathrm{P}$-MRS spectra were obtained every $30 \mathrm{~s}$ throughout the experiment.

Static handgrip strength was determined with a strain gauge dynamometer (Caspersen and Nielsen, Copenhagen, Denmark) as the highest of three maximal voluntary contractions (MVC). The $15 \%$ and $30 \%$ MVC intensities were derived from the MVC force of each subject. The handgrip task involved rhythmic contractions corresponding to the designated force $(15 \%, 30 \%$ of static MVC force) which was recorded and displayed visually for each subject as a voltage. The hand was positioned parallel to the body in a neutral position while the subjects lay supine. The forearm was cushioned to alleviate extraneous muscle activity, and the handgrip device was suspended so that subjects held it passively. Rhythmic handgrip was performed to a force corresponding to $15 \%$ and $30 \%$ MVC at a cadence of $1 \mathrm{~Hz}$ for $2 \mathrm{~min}$.

In the first experiment, NIRS-O $\mathrm{O}_{2}$ was recorded every $15 \mathrm{~s}$, venous blood sampled every $30 \mathrm{~s}$ and arterial blood after $1 \mathrm{~min}$. At $5 \mathrm{~s}$ before the end of exercise, the occlusion cuff was inflated and the PEMI interval initiated. During PEMI, NIRS- $\mathrm{O}_{2}$ and venous blood were obtained every $15 \mathrm{~s}$ for $3 \mathrm{~min}$. The cuff was then deflated and measurements were repeated as after ischaemia at rest.

After a further $20 \mathrm{~min}$ of recovery, the protocol was repeated at $30 \%$ MVC. Adequacy of the recovery periods was established by ensuring that the lactate concentration of venous blood and $\mathrm{pH}$ had returned to the level at rest [0.9 (SEM 0.01) and 7.38 (SEM $0.01) \mathrm{mmol} \cdot \mathrm{l}^{-1}$, respectively]. The protocol was repeated on a separate day for ${ }^{31} \mathrm{P}-\mathrm{MRS}$; and again for forearm blood flow by ultrasound Doppler and total $\mathrm{Hb}$ derived by NIRS. During the ${ }^{31} \mathrm{P}$ MRS study, spectra were obtained every $30 \mathrm{~s}$ during handgrip, PEMI, and recovery. The NIRS-determined total $\mathrm{Hb}$ was determined every $15 \mathrm{~s}$ during handgrip and PEMI, and every $5 \mathrm{~s}$ during the recovery. Doppler velocity spectra and arterial diameter were determined continuously and flow calculated every $30 \mathrm{~s}$ during handgrip and PEMI, and every $5 \mathrm{~s}$ during the recovery. During the ${ }^{31} \mathrm{P}$-MRS study, venous blood was also obtained to determine whether $S_{\mathrm{v}} \mathrm{O}_{2}$ differed between days.
Near infrared spectroscopy

An INVOS 3100 (Somanetic Corporation, Troy, MI) and a NIRO 500 (Hamamatsu, Japan) was used to determine muscle oxygen saturation. The optodes of the instrument were positioned over the prominence of the flexor digitorum superficialis muscle, located during passive extension of the wrist and voluntary grip contraction. The INVOS apparatus used light at 730 and $810 \mathrm{~nm}$ wavelengths to evaluate light attenuation in the tissue with a depth proportional to the separation between the optodes. The NIRS-O saturation was calculated by enhancing the signal from deep tissues using the method described previously by Pollard et al. (1996). The optodes were placed at a distance of 3 and $4 \mathrm{~cm}$, and with this separation it was expected that light would penetrate to the depth of the flexor digitorum profundus and carpi radialis muscles, all of which have been shown to engage in handgrip exercise (Mizuno et al. 1990; Van der Zee et al. 1992).

Changes in total $\mathrm{Hb}$ were calculated relative to the resting level from data obtained by the NIRO 500, which used four wavelengths with a photo-multiplier. The emitting and receiving optodes were placed $3.5 \mathrm{~cm}$ apart, and a differential pathlength factor of 3.59 for forearm muscle was used to account for the scattering of light in the tissue as proposed by Van der Zee et al. (1992).

\section{Magnetic resonance spectroscopy}

The ${ }^{31} \mathrm{P}-\mathrm{MRS}$ was carried out with a Vivospec spectrometer (Otsuka Electronics) interfaced to a $80-\mathrm{cm}$ long, $26-\mathrm{cm}$ bore $2.9-\mathrm{T}$ magnet (Magnex Scientific, Abingdon, UK). Each subjects sat with the dominant arm placed in the magnet. A 4-cm diameter, two-turn inductively driven surface coil was placed in the position marked for NIRS and a non-magnetic strain gauge dynamometer (PFN Teknik, Copenhagen, Denmark) was held passively in the hand. Homogeneity of the magnetic field was optimized by shimming on the proton signal. Line width at the start was less than 0.5 parts per million. The ${ }^{31} \mathrm{P}-\mathrm{MRS}$ spectra were obtained at $49.83 \mathrm{MHz}$ by single $90^{\circ}$ pulse excitations with pulse power and width optimized by the height of the phosphocreatine (PCr) peak. The PCr, inorganic phosphate $\left(\mathrm{P}_{\mathrm{i}}\right)$, and $\gamma$ adenosine triphosphate (ATP) spectra were collected in 2000 points over $205 \mathrm{~ms}$ with $6 \mathrm{~s}$ interpulse delay. Data were acquired in 2-min blocks at rest and in 30-s blocks during exercise and recovery. The signal to noise ratio at rest ranged from 12 to 16 . Before Fourier transformation, data were multiplied by $5-\mathrm{Hz}$ exponential line broadening. Preceded by baseline correction, integration of peak areas was performed by a least squares method assuming Lorenzian line shape. This procedure has been shown to provide good agreement with biochemical evaluation of PCr and ATP concentrations in muscle biopsies (Bangsbo et al. 1993).

\section{Blood sampling}

A catheter was inserted towards the hand into a deep vein in the antecubital space. After $2 \mathrm{ml}$ of blood had been discarded, a 1-ml sample was collected anaerobically in heparinized syringes and immediately placed on ice. The catheter was flushed with 1 to $2 \mathrm{ml}$ of saline at rest and during handgrip, while during ischaemia, the exact volume of the catheter and extension line $(0.8 \mathrm{ml})$ was used. For arterial blood, a catheter was placed in the brachial artery. The $S_{\mathrm{v}} \mathrm{O}_{2}$ and oxygen saturation in arterial blood $\left(\mathrm{SaO}_{2}\right)$ were determined by haemoximetry (OSM3, Radiometer, Copenhagen, Denmark), pH by an ABL-3 apparatus (Radiometer), and lactate concentration by a YSI 2300 analyser (Yellow Springs, Ohio).

\section{Ultrasound Doppler}

An ultrasound Doppler (CFM 800, Vingmed, Horten, Norway), equipped with an annular phased-array transducer probe (Ving- 
med) operating at an imaging frequency of $7.5 \mathrm{MHz}$, was used for imaging of the brachial artery (Rådegran 1997). The artery was insonated at a perpendicular angle. Its diameter was determined from two-dimensional (2-D) longitudinal image sections along the central path of the ultrasound beam, where optimal spatial resolution occurs. Systolic and diastolic diameters for each cardiac cycle were individually determined. A diameter corresponding to one third of the systolic and two thirds of the diastolic values $(\varnothing$ $=\varnothing$ systole $_{1 / 3}+\varnothing$ diastole $_{2 / 3}$ ) was used to represent of diameter over the cardiac cycle. A variable Doppler frequency of 4 $6 \mathrm{MHz}$, operating in high-pulsed repetition frequency mode (4$36 \mathrm{KHz}$ ) was used for blood velocity measurements. The velocity was measured during real-time 2-D visualization of the artery. This procedure allowed centring and size adjustment of the sample volume across the diameter of the vessel and thus over the full spatial distribution of the velocity profile. A PC with an A-D converter allowed transfer and storage of the Doppler signals and heart rates determined from the electrocardiogram. The mean blood velocity $(\bar{v})$ was angle-corrected, time and space averaged, and amplitude weighted. Volume flow was calculated from the continuous $\bar{v}$ and the arterial radius $(r)$ as $\dot{Q}=\bar{v} \pi r^{2}$. At rest, during handgrip and PEMI, blood flow was determined from $\bar{v}$ collected over ten cardiac cycles in the last $30 \mathrm{~s}$ of each minute, and over five cycles during recovery.

\section{Calculations}

Since the NIR signal has been shown only to provide relative changes due to the unknown optical pathlength in the tissue (Chance et al. 1988), the NIRS-O ${ }_{2}$ data were normalized by defining the range between fully oxidized and reduced states for each subject as recommended by Chance et al. (1992) and Hamaoka et al. (1996). The highest value was observed during reperfusion after PEMI, and the lowest ("0"\%) was obtained during PEMI after $30 \%$ MVC. The muscle metabolism $\left(\mathrm{MO}_{2}: \mu \mathrm{mol} \cdot \mathrm{s}^{-1}\right)$ was determined using the initial rate of $\mathrm{NIRS}-\mathrm{O}_{2}(\%)$ desaturation during ischaemia (DeBlasi et al. 1992; Hamaoka et al. 1996), and applying a muscle oxygen store of $0.35 \mathrm{mmol}$ (Hamaoka et al. 1996). Forearm oxygen consumption $\left(\dot{V} \mathrm{O}_{2}\right)$ was determined as the product of the blood flow in the brachial artery and the arterio-venous oxygen difference, of which $\mathrm{SaO}_{2}$ [97 (SEM 1)\%] never changed significantly.

Free adenosine diphosphate concentration [ADP] was calculated from the MRS data as $\left([\mathrm{Cr}] \times\left[\mathrm{ATP} \times 10^{-3}\right]\right) /[\mathrm{PCr}] \times$ $\left.\left[\mathrm{H}^{+}\right] \times 1.66 \times 10^{9}\right)$ assuming a creatine kinase equilibrium, a rest ATP concentration of $5.5 \mathrm{mmol} \cdot \mathrm{kg}^{-1}$ wet mass and a $[\mathrm{PCr}] \times([\mathrm{PCr}]+[\mathrm{Cr}])$ ratio at rest of 0.6 . The $\mathrm{pH}$ was calculated according to Taylor et al. (1983) and in the case of $\mathrm{P}_{\mathrm{i}}$ splitting (Mizuno et al. 1994), a weighted average of the $P_{i}$ peaks was used.

During rhythmic handgrip, anaerobic ATP production was calculated as $\Delta \mathrm{PCr}+3 / 2(\beta \Delta \mathrm{pH}+\mathrm{k} \Delta \mathrm{PCr})$, where $\mathrm{k}=1 /$ $\left(1+10^{\mathrm{pH}-6.75}\right)$ and the buffer capacity was taken as 40 slykes as shown by Kemp and Radda (1994). It was assumed that the increase in $\mathrm{H}^{+}$was accounted for only by lactate production and that only an insignificant release of $\mathrm{H}^{+}$and lactate took place from muscle during the measurement.

The aerobic ATP production was calculated from forearm $\dot{V} \mathrm{O}_{2}$ and NIRS-determined $\mathrm{MO}_{2}$ assuming a phosphorus to oxygen ratio of 2.5. The ATP production was expressed as millimoles per kilogram of muscle assuming a forearm flexor volume of $300 \mathrm{ml}$ (Winters and Woo, 1990) and a muscle density of $1.05 \cdot \mathrm{kg}^{-1}$.

Changes with time and between conditions were evaluated using the Friedman test and if found significant, such differences were located by Wilcoxon's test. Interdependencies were determined by Spearman's test. Also, to obtain the half-time responses $\left(t_{1 / 2}\right)$, relationships were fitted by a least squares method. Differences were considered significant if $P$ was less than 0.05 .

\section{Results}

\section{Ischaemia at rest}

While $S_{\mathrm{V}} \mathrm{O}_{2}$ decreased during the initial $5 \mathrm{~min}$ [from 71 (SEM 3) to 59 (SEM 2)\%], the decrease in NIRS-O 2 was much more pronounced, and it reached 3 (SEM 1$) \%$ (Fig. 1) and the two variables were correlated $(r=0.6$; $P<0.01)$. The initial rate of reduction in $\mathrm{NIRS}-\mathrm{O}_{2}$ was by $0.27 \% \cdot \mathrm{s}^{-1}$ corresponding to a $\mathrm{MO}_{2}$ of $1.3 \mu \mathrm{mol} \cdot \mathrm{s}^{-1}$. The $\mathrm{P}_{\mathrm{I}}: \mathrm{PCr}$ rose after 4 to $5 \mathrm{~min}$ [from 0.13 (SEM 0.01) to reach 0.30 (SEM 0.01)] as did ADP [25 (SEM 1) to 34 (SEM 3) $\mu \mathrm{mol} \cdot \mathrm{kg}^{-1}$; Fig. 1]. Both muscle and venous $\mathrm{pH}$ remained at the values seen at rest [7.05 (SEM 0.02) and 7.38 (SEM 0.02), respectively].

\section{Recovery}

Upon release of the cuff, $S_{\mathrm{V}} \mathrm{O}_{2}$ decreased initially to 38 (SEM 2)\% (Fig. 1). The subsequent recovery was with a
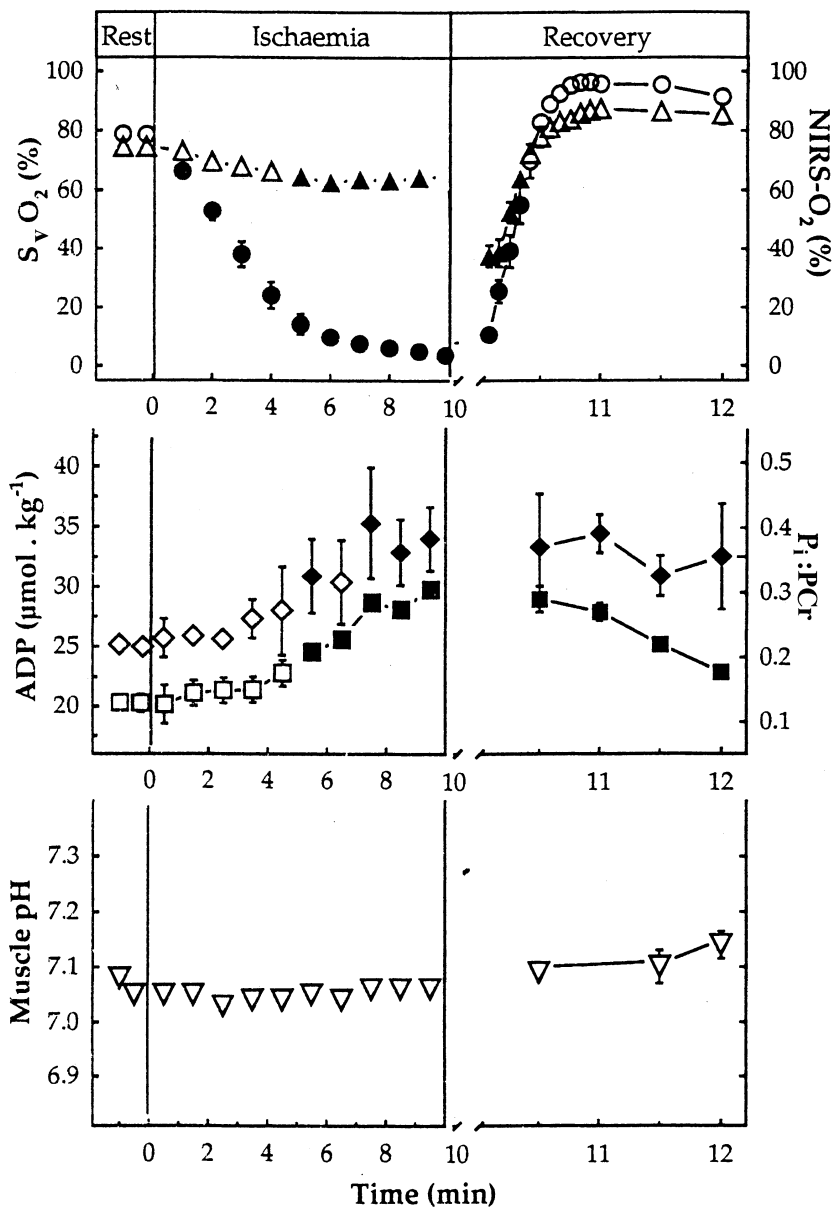

Fig. 1 Forearm metabolic variables at rest, during forearm is-

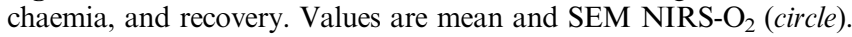
Near infrared spectroscopy of forearm flexor muscles, $S_{\mathrm{v}} \mathrm{O}_{2}$ (triangle) oxygen saturation of venous blood, $\mathrm{Pi} P \mathrm{PCr}$ (squares) ratio of muscle inorganic phosphate to creatine phosphate, ADP (diamonds) adenosine diphosphate; muscle $p H$ (inverted triangles). Filled symbol different from rest $P<0.05$ 
$\mathrm{t}_{1 / 2}$ of 13 (SEM 1s) and after 1 min, the peak value was 87 (SEM 1)\% (16\% above rest). Also, the NIRS-O ${ }_{2}$ recovery had a $t_{1 / 2}$ of 13 (SEM 1) s and it had a peak of 97 (SEM 1)\% (20\% above rest) that coincided with the peak for $S_{\mathrm{v}} \mathrm{O}_{2}$, and the two were correlated $(r=0.82$; $P<0.01)$. The Pi:PCr recovered, while ADP did not reach the rest level. Venous and muscle $\mathrm{pH}$ did not change.

Rhythmic handgrip exercise at $15 \%$ maximal voluntary contraction

The $S_{\mathrm{v}} \mathrm{O}_{2}$ fell after $30 \mathrm{~s}$, reached 31 (SEM 4)\% after $1 \mathrm{~min}$ and then remained stable (Fig. 2). After $30 \mathrm{~s}$, NIRS-O ${ }_{2}$ also decreased [to 70 (SEM 3)\%], and the decrease continued to an end value of 67 (SEM 3)\%. The $t_{1 / 2}$ was 24 (SEM 6) and 15 (SEM 1) s, respectively, and the two variables were correlated $(r=0.64$; $P<0.01)$.

Fig. 2 Forearm metabolic and blood flow variables at rest, during rhythmic handgrip exercise $(R H G)$, post-exercise muscle ischaemia $(P E M I)$, and recovery. Values are mean and SEM. Circles $15 \%$ maximal voluntary contraction (MVC) diamonds 30\% MVC. $S_{\mathrm{V}} \mathrm{O}_{2}$ oxygen saturation, in venous blood, $N I R S-\mathrm{O}_{2}$ near infrared spectroscopy determined $\mathrm{O}_{2}$ saturation, $P i: P C r$ muscle inorganic phosphate to phosphocreatine ratio, $P C r$ muscle phosphocreatine, $A D P$ adenosine diphosphate, $F B F$ forearm blood flow, $V \mathrm{O}_{2}$ forearm oxygen upake, $T H b$ NIRS determined total haemoglobin. Filled symbol different from rest $P<0.05,{ }^{*}$ difference between intensities $P<0.05$
The Pi:PCr reached 1.0 (SEM 0.2) and ADP rose to a plateau of 41 (SEM 5) $\mu \mathrm{mol} \cdot \mathrm{kg}^{-1}$ as PCr fell to 60 (SEM 6)\% of the rest level (Fig. 3). Within $1 \mathrm{~min}$, muscle $\mathrm{pH}$ fell to 6.8 (SEM 0.03); likewise, venous $\mathrm{pH}$ (after $90 \mathrm{~s}$ ) fell to 7.30 (SEM 0.01). During the MRS study, the end-handgrip $S_{\mathrm{v}} \mathrm{O}_{2}$ was similar [30 (SEM 5)\% vs 31 (SEM 4)] to the value on the previous day when NIRS-O $\mathrm{O}_{2}$ and $S_{\mathrm{v}} \mathrm{O}_{2}$ were determined.

Forearm blood flow increased from 77 (SEM 6) to 352 (SEM 39) $\mathrm{ml} \cdot \mathrm{min}^{-1}$ and $\dot{V} \mathrm{O}_{2}$ from 4.0 (SEM 0.2) to 46 (SEM 3) $\mathrm{ml} \cdot \mathrm{min}^{-1}$ (Fig. 2). The mean brachial artery diameter $(1 / 3 \varnothing$ systolic $+2 / 3 \varnothing$ diastolic) was 4.4 (SEM 0.1) $\mathrm{mm}$. Relative to rest, total $\mathrm{Hb}$ fell by 10 (SEM 4) $\mu \mathrm{mol}$ at the beginning of handgrip exercise and subsequently recovered 6 (SEM 5) $\mu \mathrm{mol}$. The anaerobic ATP production was 99 (SEM 20) $\mathrm{mmol} \cdot \mathrm{kg}^{-1}$ and the aerobic production 52 (SEM 4) $\mathrm{mmol} \cdot \mathrm{kg}^{-1}$ (Fig. 3).

Post-exercise muscle ischaemia

Paradoxically, $S_{\mathrm{v}} \mathrm{O}_{2}$ increased throughout the ischaemic period to reach an end value of 39 (SEM 3)\% (Fig. 2). In contrast, $\mathrm{NIRS}_{2} \mathrm{O}_{2}$ fell to a nadir of 9 (SEM 1$) \%$ with a $t_{1 / 2}$ of 48 (SEM 2) $\mathrm{s}$ and the two variables did not correlate. The initial NIRS-O $\mathrm{O}_{2}$ rate of reduction was approximately twice that established during ischaemia at rest and $\mathrm{MO}_{2}$ was $2.3 \mu \mathrm{mol} \cdot \mathrm{s}^{-1}$. The $\mathrm{Pi}: \mathrm{PCr}, \mathrm{PCr}$, muscle $\mathrm{pH}, \mathrm{ADP}$, and venous $\mathrm{pH}$ all remained similar to the end-exercise values. The $\mathrm{Hb}$ first rose by 4 (SEM 1)
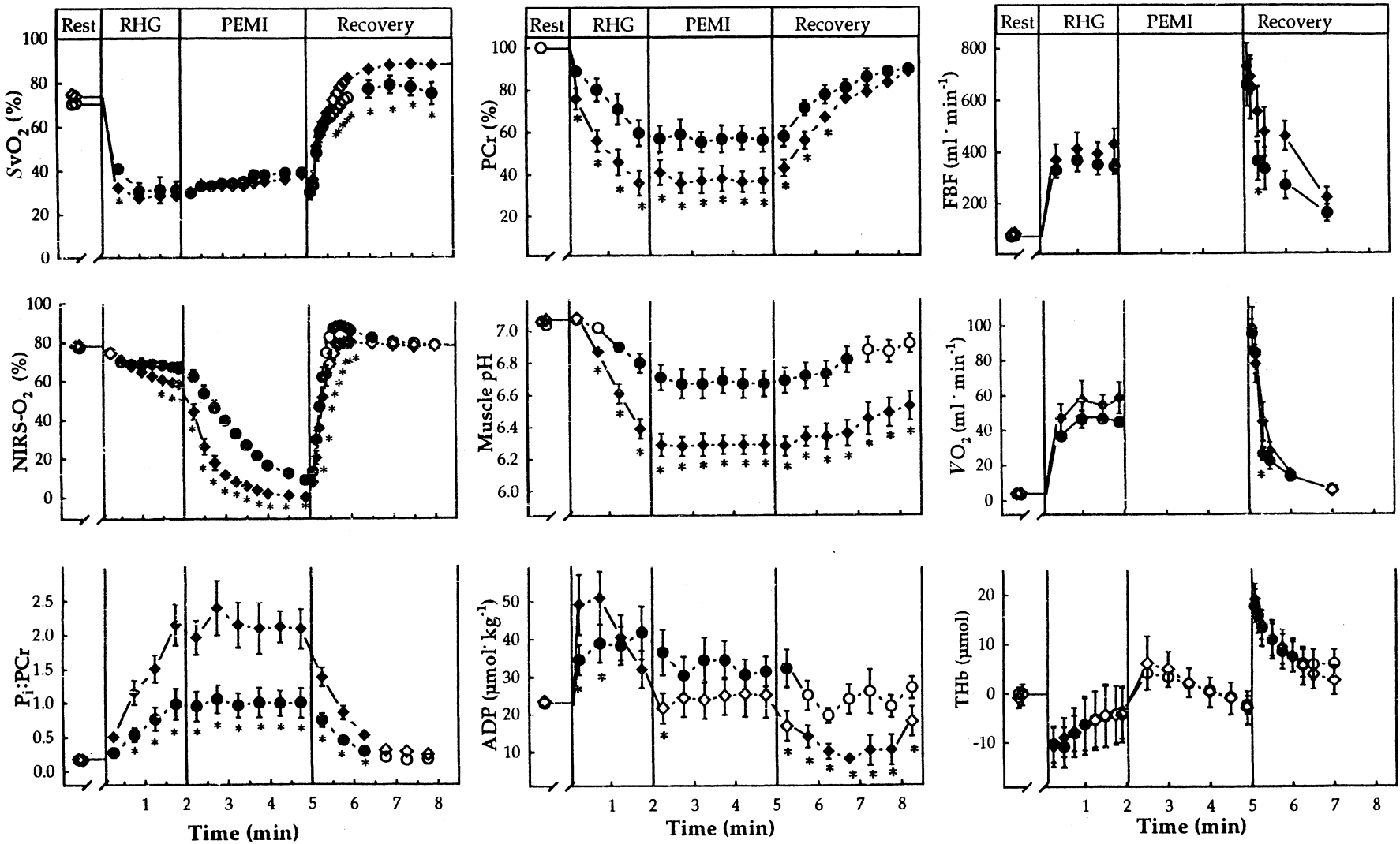

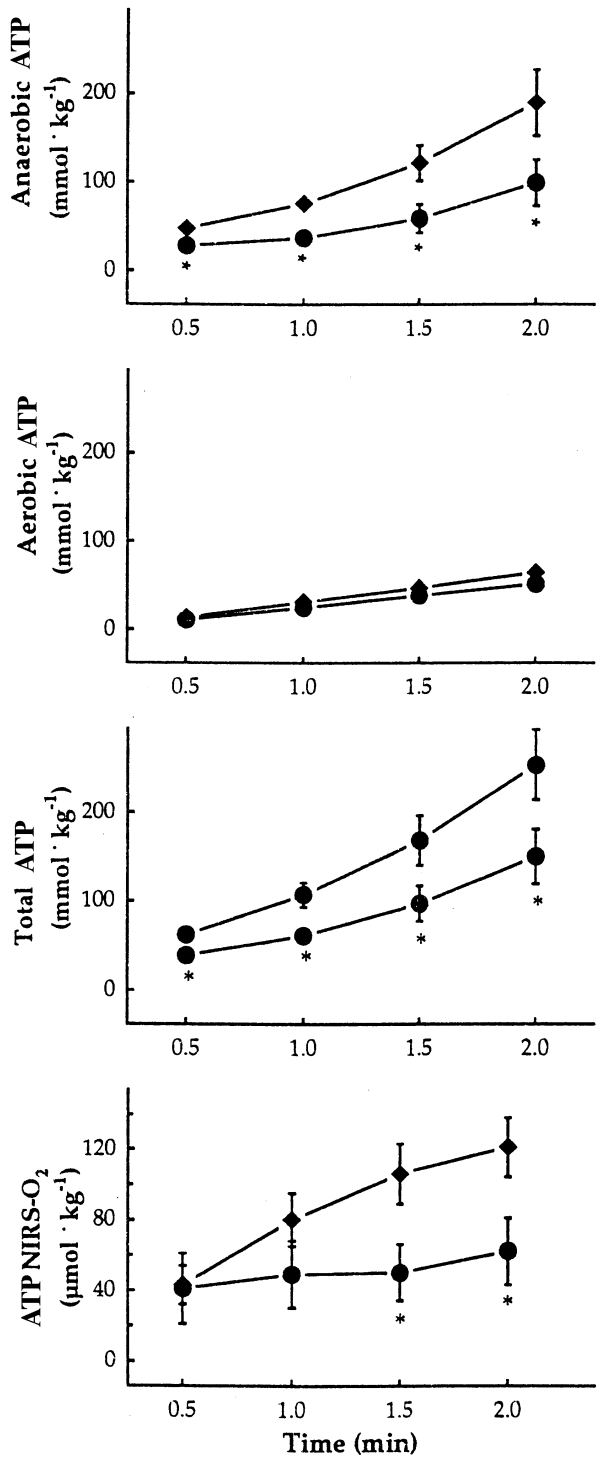

Fig. 3 Estimates of anaerobic and aerobic and anaerobic adenosine triphosphate $(A T P)$ production; the sum of the two, and ATP turnover based on the near infrared spectroscopy (NIRS)-determined muscle metabolism for rhythmic handgrip exercise. Values are mean and SEM Circles 15\% maximal voluntary contraction (MVC); diamonds 30\% MVC. * Difference between intensities $P<0.05$

$\mu \mathrm{mol}$ with cuff inflation, and then fell 2 (SEM 2) $\mu \mathrm{mol}$ as $18 \mathrm{ml}$ of blood was withdrawn.

\section{Recovery}

The $S_{\mathrm{v}} \mathrm{O}_{2}$ decreased immediately after release of the cuff followed by a recovery with a $t_{1 / 2}$ of 15 (SEM 2) s (Fig. 2). The rest value was attained in 30 (SEM 3) s; and after $90 \mathrm{~s}$ it reached a peak of 78 (SEM 4)\% corresponding to $7 \%$ above rest. For $\mathrm{NIRS}-\mathrm{O}_{2}$ the recovery was with a $t_{1 / 2}$ of 15 (SEM 1) s to reach the value at rest in 30 (SEM 6) $\mathrm{s}$ and the peak of 88 (SEM 1)\% appeared after $45 \mathrm{~s}\left(12 \%\right.$ above rest). Thus, NIRS-O ${ }_{2}$ and $S_{\mathrm{v}} \mathrm{O}_{2}$ were correlated $(r=0.79 ; P<0.01)$.
The Pi:PCr recovered with a $t_{1 / 2}$ of $27($ SEM 5) s (Fig. 2). The ADP returned to the rest value by $60 \mathrm{~s}$ and muscle $\mathrm{pH}$ recovered after $2.5 \mathrm{~min}$. Immediately after release of the cuff, venous blood $\mathrm{pH}$, as well as $S_{\mathrm{v}} \mathrm{O}_{2}$, fell marginally, and then recovered towards the rest value (Figs. 2, 4).

In the first $5 \mathrm{~s}$, blood flow rose to 659 (SEM 85) $\mathrm{ml}$. $\min ^{-1}$ and then returned towards the rest level (Fig. 2). After $1 \mathrm{~min}, \dot{V} \mathrm{O}_{2}$ was $13.5(\mathrm{SEM} 2) \mathrm{ml} \cdot \mathrm{min}^{-1}$. The $\mathrm{Hb}$ rose to 17.6 (SEM 3) $\mu \mathrm{mol}$ above the rest level and it recovered after $1 \mathrm{~min}$.

Rhythmic handgrip exercise at 30\% maximal voluntary contraction

Within $30 \mathrm{~s}, S_{\mathrm{v}} \mathrm{O}_{2}$ fell to $32(\mathrm{SEM} 3) \%$, reached 29 (SEM 3)\% after $1 \mathrm{~min}$, and then, as during 15\% MVC, remained stable (Fig. 2). The $t_{1 / 2}$ was 9.0 (SEM 0.7) s and after $30 \mathrm{~s}$ it was not significantly different from the $15 \%$ MVC value. The NIRS-O ${ }_{2}$ fell to 70 (SEM 2)\% after $30 \mathrm{~s}$ and reached 58 (SEM 3) \% by the end of exercise; thus, it was lower than during $15 \% \mathrm{MVC}$ in the last $90 \mathrm{~s}$. The $t_{1 / 2}$ was 72 (SEM 7) s and NIRS-O ${ }_{2}$ was correlated to $S_{\mathrm{v}} \mathrm{O}_{2}(r=0.56 ; P<0.01)$.

The Pi:PCr was higher than at $15 \%$ MVC after $60 \mathrm{~s}$ and reached 2.2 (SEM 0.3) with a slope twice that at $15 \%$ MVC (Fig. 2). The PCr fell to 36 (SEM 6) $\%$ of the rest level. The rise in ADP was above the $15 \% \mathrm{MVC}$ value $\left[51\right.$ (SEM 5) $\mu \mathrm{mol} \cdot \mathrm{kg}^{-1}$ ], but by the end of exercise, it approached the rest level. After $30 \mathrm{~s}$, venous blood and muscle pH fell to 7.23 (SEM 0.02) and 6.38 (SEM 0.06), respectively (Figs. 2, 4). Again during the MRS study, the end-handgrip $S_{\mathrm{v}} \mathrm{O}_{2}$ was similar [28 (SEM 4)\%] to the value [29 (SEM 3)\%] on the previous day when NIRS-O $\mathrm{O}_{2}$ and $S_{\mathrm{v}} \mathrm{O}_{2}$ were determined.

The flow was 431 (SEM 55) $\mathrm{ml} \cdot \mathrm{min}^{-1}$ and the $\dot{V} \mathrm{O}_{2}$ 58.6 (SEM 9) $\mathrm{ml} \cdot \mathrm{min}^{-1}$ (Fig. 2). The $\mathrm{Hb}$ fell 10 (SEM 4) $\mu \mathrm{mol}$ below the level at rest and recovered 5 (SEM 5) $\mu \mathrm{mol}$ with no significant difference between the two exercise intensities. The anaerobic ATP production

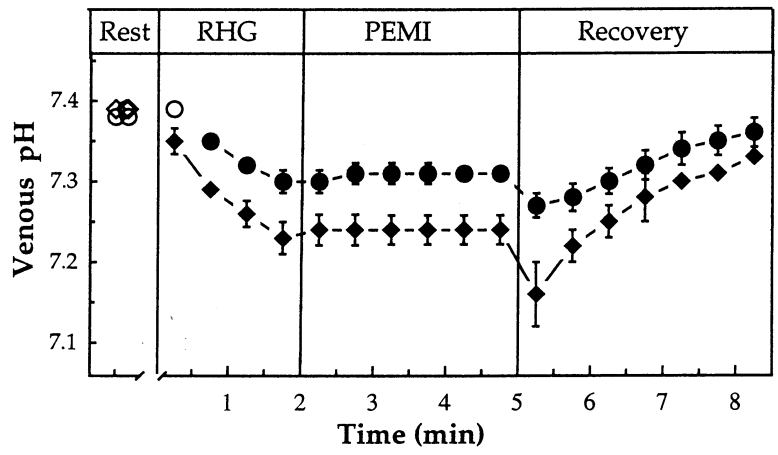

Fig. 4 Venous blood $\mathrm{pH}$ at rest, during rhythmic handgrip $(R H G)$, post-exercise muscle ischaemia $(P E M I)$, and recovery. Values are mean and SEM. Circles 15\% maximal voluntary contraction (MVC), and diamonds 30\% MVC. Filled symbol different from rest $P<0.05$, * difference between intensities $P<0.05$ 
reached 190 (SEM 37) $\mathrm{mmol} \cdot \mathrm{kg}^{-1}$, or twice the $15 \%$ MVC value (Fig. 3). The aerobic production was 64 (SEM 10) $\mathrm{mmol} \cdot \mathrm{kg}^{-1}$; only $25 \%$ higher than at the lower exercise intensity.

\section{Post-exercise muscle ischaemia}

As during 15\% MVC, $S_{\mathrm{V}} \mathrm{O}_{2}$ increased to 38 (SEM 1)\% (Fig. 2). In contrast, NIRS-O $\mathrm{O}_{2}$ decreased with a $t_{1 / 2}$ of 21 (SEM 2) s to reach " 0 ", and the two set of data did not correlate. Thus, NIRS-O $\mathrm{O}_{2}$ was always lower than during $15 \% \mathrm{MVC}$ and the initial decrease showed a slope twice $(\times 2.2)$ that of $15 \% \mathrm{MVC}$ with a $\mathrm{MO}_{2}$ of $5.1 \mu \mathrm{mol} \cdot \mathrm{s}^{-1}$.

The Pi:PCr remained at the end-exercise value thus being higher than after 15\% MVC (Fig. 2). Both $\mathrm{PCr}$ and $\mathrm{ADP}$, as muscle and venous $\mathrm{pH}$, were similar to the end-exercise values. The $\mathrm{Hb}$ increased 6 (SEM 5) $\mu \mathrm{mol}$ above the rest level with cuff inflation and subsequently fell to 3 (SEM 3) $\mu \mathrm{mol}$ below the rest level.

\section{Recovery}

The $S_{\mathrm{V}} \mathrm{O}_{2}$ recovered with a $t_{1 / 2}$ of $12(\mathrm{SEM} 1) \mathrm{s}$, the rest value was reached in 35 (SEM 2) s, and after this point it was higher than after 15\% MVC. (Fig. 2). After 1 min, it was 14 (SEM) $1 \%$ above the level at rest 89 (SEM $1) \%$. The NIRS-O ${ }_{2}$ recovered with a $t_{1 / 2}$ of 15 (SEM 1$) \mathrm{s}$ and while it also reached the rest value in 30 (SEM 4) s, it did not exceed that level and was thereby lower than after $15 \%$ MVC. The correlation coefficient between $S_{\mathrm{v}} \mathrm{O}_{2}$ and NIRS-O ${ }_{2}$ was $0.84(P<0.01)$.

The Pi:PCr recovered with a $t_{1 / 2}$ of 31 (SEM 4) s and it remained higher for $2 \mathrm{~min}$ than after both ischaemia at rest and 15\% MVC PEMI (Fig. 2). Similarly, $\mathrm{PCr}$ recovered but it was lower than after $15 \% \mathrm{MVC}$ for the first $90 \mathrm{~s}$. The ADP decreased from min 1-3 of recovery and then returned to the rest level. Venous $\mathrm{pH}$ fell initially to 7.16 (SEM 0.04) and then, as with muscle $\mathrm{pH}$, approached the level at rest. For all phases of the experiment, muscle and venous blood $\mathrm{pH}$ were correlated $(r=0.8 ; P<0.01)$.

Blood flow rose to $730(\mathrm{SEM} 110) \mathrm{ml} \cdot \mathrm{min}^{-1}$ and $\dot{V} \mathrm{O}_{2}$ was 15 (SEM 2) $\mathrm{ml} \cdot \min ^{-1}$ after 1 min (Fig. 2). The $\mathrm{Hb}$ increased to 19 (SEM 3) $\mu \mathrm{mol}$ above the rest level and then recovered after 1 min.

\section{Discussion}

This study compared two methods for studying patterns of oxgyen saturation and metabolic rate during rhythmic handgrip exercise, PEMI, and recovery. We found changes in NIRS $\mathrm{O}_{2}$ saturation of the forearm flexor muscles during handgrip consistent with MRS-determined metabolic rate, but not reflected in regional $S_{\mathrm{v}} \mathrm{O}_{2}$ and forearm $\dot{V} \mathrm{O}_{2}$. Also, during both rest and PEMI, the kinetics of $S_{\mathrm{v}} \mathrm{O}_{2}$ and NIRS-O $\mathrm{O}_{2}$ were different: while $S_{\mathrm{v}} \mathrm{O}_{2}$ established a plateau, the NIRS signal continued to decrease.

During ischaemia at rest, NIRS- $\mathrm{O}_{2}$ and $\mathrm{S}_{\mathrm{v}} \mathrm{O}_{2}$ were correlated, but the fall in $S_{\mathrm{v}} \mathrm{O}_{2}$ was relatively small compared to NIRS-O $\mathrm{O}_{2}$. During post-exercise muscle ischaemia, the two variables were not correlated and there was in fact a slight increase in $S_{\mathrm{v}} \mathrm{O}_{2}$ while NIRS-O ${ }_{2}$ fell markedly. The common finding that $S_{\mathrm{v}} \mathrm{O}_{2}$ remained quite constant would indicate that the blood sampled came predominantly from the veins with little contribution from the capillaries, although the NIRS did detect a reduction of $\mathrm{Hb}$ with each blood withdrawal. A possible explanation for the slight increase in $S_{\mathrm{v}} \mathrm{O}_{2}$ during postexercise muscle ischaemia is that the vascular bed of the forearm was provided with blood from the veins of the upper arm during the rapid inflation of the occlusion cuff, as suggested by the increase in total $\mathrm{Hb}$. This blood would have been unlikely to have represented the metabolism in the forearm muscles, and the influence of translocated blood may have been more pronounced after exercise because the blood volume in the forearm would have been lowered by the muscle pump.

With unimpeded blood flow to the forearm during rhythmic handgrip exercise, and especially during reperfusion after PEMI, it is much more likely that $S_{\mathrm{v}} \mathrm{O}_{2}$ would have reflected saturation in the muscle capillaries and, in fact, the correlation between NIRS-O $\mathrm{O}_{2}$ and $S_{\mathrm{v}} \mathrm{O}_{2}$ became better the higher the flow: during rhythmic handgrip the $r$ was 0.6 at a flow of $400 \mathrm{ml} \cdot \mathrm{min}^{-1}$ and during reperfusion after PEMI, the $r$ was 0.82 at a forearm flow of $700 \mathrm{ml} \cdot \mathrm{min}^{-1}$.

During rhythmic handgrip exercise, it remains puzzling why $S_{\mathrm{v}} \mathrm{O}_{2}$ did not decrease from $15 \%$ to $30 \%$ MVC although flow was limited, but this pattern is in line with the results of Wahren (1976). This occurred even though the $\mathrm{pH}$ of blood was lower (7.23 vs 7.30) which would support desaturation upon the passage through the capillaries (Stringer et al. 1994). Thus, the unchanged $S_{\mathrm{V}} \mathrm{O}_{2}$, despite a fall in $\mathrm{pH}$, may indicate a diffusion limitation between the capillaries and forearm muscles. It could be that the forearm flexor muscles constituted so small a fraction of the forearm vascular bed that we were unable to detect the corresponding change. However, during handgrip exercise most of the forearm muscles have been shown to become engaged (Mizuno et al. 1994), especially at $30 \%$ MVC, making it unlikely that the venous blood sampled at the elbow was not influenced significantly by the muscle activity.

Furthermore, if the unchanged $\mathrm{S}_{\mathrm{v}} \mathrm{O}_{2}$ reflected an admixture of blood from other less active tissues this would possibly have occurred also for venous $\mathrm{pH}$. The fact that $\dot{V} \mathrm{O}_{2}$, did the as flow, increased to a much higher level after the release of the upper arm cuff does not contradict an argument for a diffusion limitation. However, with reperfusion, $\dot{V} \mathrm{O}_{2}$ represents only partly the metabolic rate as resaturation of both $\mathrm{Hb}$ and $\mathrm{Mb}$ would have been included in the value calculated. However, the resaturation of $\mathrm{Mb}$ requires diffusion of oxygen into the cell. Thus, either blood admixture or a lower $\mathrm{MbO}_{2}$ could 
have explained the opposite patterns of peak NIRS- $\mathrm{O}_{2}$ and $S_{\mathrm{v}} \mathrm{O}_{2}$ during recovery after $15 \%$ and $30 \% \mathrm{MVC}$.

The reduction in total $\mathrm{Hb}$ at the onset of exercise reflected the fact that the muscle pump directs blood towards the heart and the subsequent recovery towards the rest level during handgrip exercise that the muscle became hyperaemic. Furthermore, during the recovery from PEMI, the highest value for total $\mathrm{Hb}$ was noted as being concomitant with the highest flow being elicited in the passive forearm in response to reperfusion hyperaemia. During handgrip exercise, the forearm blood flow was only $55 \%$ of the value noted during reperfusion after PEMI, and almost identical at the two exercise intensities (352 and $431 \mathrm{ml} \cdot \mathrm{min}^{-1}$ ) which supports the suggestion that has been made of a circulatory limitation to $V \mathrm{O}_{2}$, even when the capacity of the heart is unlikely to be challenged (Kagaya and Ogita 1992). In humans involved in exercise with a larger muscle mass, a maximal flow rate has been reported only during arm cranking. In that situation, it has been reported that an increasing exercise intensity is accomplished by an increasing involvement of the muscles of the upper body (Secher and Saltin 1994). Compared to the exercise intensities normally used during, for example leg exercise, the $30 \%$ $\mathrm{MVC}$, in fact represented a maximal effort, as the force achieved fell to 94 (SEM 2)\% of the intended level in the last seconds of the handgrip.

One explanation for the lack of a substantial increase in blood flow from $15 \%$ to $30 \%$ MVC could be that flow was impeded by the mechanical forces of muscle contraction. It was apparent from the Doppler velocity spectra that flow to the muscle at $30 \%$ MVC occurred almost entirely during relaxation. Alternatively, forearm flow may have been limited by sympathetic vasoconstriction, which then was eliminated during the reperfusion. During rhythmic handgrip exercise Joyner et al. (1992) has argued for a higher forearm flow when the sympathetic outflow to the arm is blocked after application of local anesthetics to the stellate ganglion.

The NIRS apparatus was unable to distinguish between changes in saturation of $\mathrm{Hb}$ and $\mathrm{Mb}$. Thus, a limitation of this study was that we were unable to determine the extent to which the discrepancies between NIRS-O ${ }_{2}$ and $S_{\mathrm{v}} \mathrm{O}_{2}$ during handgrip were due to differences in $\mathrm{MbO}_{2}$. Yet, the marked decrease in $S_{\mathrm{v}} \mathrm{O}_{2}$ during exercise $(40 \%)$ with a relatively stable NIRS-O $2(\sim 20 \%$ reduction), as opposed to the stable $S_{\mathrm{v}} \mathrm{O}_{2}$ during PEMI with a drop in NIRS-O $\mathrm{O}_{2}$ to its lowest level $(\sim 60 \%$ lower than during handgrip), supports the suggestion that $\mathrm{MbO}_{2}$ becomes desaturated only during PEMI (Wang et al. 1990).

With no knowledge of the mechanical efficiency during rhythmic handgrip exercise, a central assumption of this study was that the forearm metabolic rate would increase in proportion to the exercise intensity. This has been established for $\mathrm{MO}_{2}$ (Belardinelli et al. 1995) and for the MRS-determined ATP turnover, but this was not the case for forearm $\dot{V} \mathrm{O}_{2}$. Thus, it was unique to NIRS$\mathrm{O}_{2}$ that it evaluated the aerobic contribution to metab- olism. In confirmation of the results of Hamaoka et al. (1996), when the muscle metabolic rate was evaluated by MRS-derived indices of ATP turnover, we found a high correlation to $\mathrm{MO}_{2}$. Notably, the muscle metabolism derived from MRS suggested an approximate twofold increase from 15 to $30 \% \mathrm{MVC}$, as did the calculation based on NIRS-O ${ }_{2}$, but not the rate derived from blood flow and the arterio-venous difference in oxygen saturation. The finding that forearm blood flow was limited and $S_{\mathrm{v}} \mathrm{O}_{2}$ did not decrease in proportion to exercise intensity makes many of the premises for modelling muscle metabolism during exercise (Severinghaus 1994) invalid.

Forearm $\dot{V} \mathrm{O}_{2}$ determined by the product of blood flow and the arterio-venous difference in oxygen saturation would suggest that anaerobic metabolism was prominent especially when the forearm was made ischaemic, both at rest and following rhythmic handgrip exercise. In that situation, NIRS- $\mathrm{O}_{2}$ became reduced, while there was no change in muscle or in venous blood $\mathrm{pH}$ as indications of glycolysis. One conclusion could be that glycolysis is coupled to the mechanical events in the muscle during contraction, leading to the decrease in $\mathrm{pH}$ only during the handgrip exercise as found by Quistorff et al. (1993). Alternatively, the oxygen store in the capillary $\mathrm{HbO}_{2}$, and in $\mathrm{MbO}_{2}$ in the muscle cells, could be large enough to provide for tissue metabolism during ischaemia after exercise was performed, precluding the need for glycolytic activity.

Towards the end of the exercise at $30 \% \mathrm{MVC}$, force was diminished (fatigue) with a comparable fall in anaerobic ATP production from 2.1 to 1.9 -fold the $15 \%$ MVC value, signifying a maintained ATP productionto-demand ratio as found by Hogan et al. (1996). Free ADP fell markedly but apparently in a mmaner unrelated to ATP turnover. The decline in NIRS- $\mathrm{O}_{2}$ and the maintained $\dot{V} \mathrm{O}_{2}$ suggested that mitochondrial respiration may not have been strictly controlled by ADP as suggested by Barstow et al. (1994).

To conclude, NIRS- $\mathrm{O}_{2}$ of forearm flexor muscles closely reflected the exercise intensity and the MRS-determined metabolic rate, but not the rate derived from blood flow and the arterio-venous difference in oxygen saturation. These findings illustrate the validity and potential advantages of NIRS-O ${ }_{2}$ for measuring muscle oxidative metabolism during exercise and ischaemia.

Acknowledgements We thank Heidi Hansen, Annette Uhlman, and $\mathrm{Ib}$ Therkelsen for their excellent technical assistance and Erling Veje for determining the wavelengths of the INVOS 3100 apparatus. This study was supported by the Danish Research Academy, The Danish National Research Foundation (504-14), The Dagmar Marschalls Fond, and by E. Kay-Hansen.

\section{References}

Bangsbo JL, Johansen L, Quistorff B, Saltin B (1993) NMR and analytic biochemical evaluation of $\mathrm{CrP}$ and nucleotides in the human calf during muscle contraction. J Appl Physiol 74:20342039 
Barstow TJ, Buchthal S, Zanconato S, Cooper DM (1994) Muscle energetics and pulmonary oxygen uptake kinetics during moderate exercise. J Appl Physiol 77:1742-1749

Belardinelli R, Barstow TJ, Porszasz J, Wasserman K (1995) Skeletal muscle oxygenation during constant work rate exercise. Med Sci Sports Exerc 27:512-519

Chance B, Nioko S, Kent J, McCully K, Fountain M, Greenfeld R, Holtom G (1988) Time resolved spectroscopy of hemoglobin and myoglobin in resting and ischaemic muscle. Anal Biochem 174:698-707

Chance B, Dait MT, Zhang C, Hamaoka T, Hagerman F (1992) Recovery from exercise induced desaturation in the quadriceps muscles of elite competitive rowers. Am J Physiol 262: C766-C775

Costes F, Barthelemy JC, Feasson L, Busso T, Geyssant A, Denis C (1996) Comparison of muscle near-infrared spectroscopy and femoral blood gases during steady-state exercise in humans. $\mathbf{J}$ Appl Physiol 80:1345-1350

DeBlasi, RA, Immacolata A, Cope M, Elwell C, Ferrari M (1992) Non-invasive measurement of forearm oxygen consumption during exercise by near infrared spectroscopy. In: Vaupel $P$, Zander R, Bruley D (eds) Oxygen transport to tissue, vol. XV, Plenum press New York, pp 685-692

Hamaoka T, Iwane H, Shimomitsu T, Katsumura T, Murase N, Nishio S, Osada T, Kurosawa Y, Chance B (1996) Noninvasive measures of oxidative metabolism on working human muscles by near infrared spectroscopy. J Appl Physiol 81:1410-1417

Hogan, MC, Kurdak SS, Arthur PG (1996) Effect of gradual reduction in $\mathrm{O}_{2}$ delivery on intracellular homeostasis in contracting skeletal muscle. J Appl Physiol 80:1313-1321

Joyner MJ, Nauss LA, Warner MA, Warner DO (1992) Sympathetic modulation of blood flow and $\mathrm{O}_{2}$ uptake in rhythmically contracting human forearm muscles Am J Physiol 263:H1078H1083

Kagaya A, Ogita F (1992) Blood flow during muscle contraction and relaxation in rhythmic exercise at different intensities. Ann Physiol Anthropol 11:251-256

Kemp GJ, Radda GK (1994) Quantitative interpretation of bioenergetic data from ${ }^{31} \mathrm{P}$ and ${ }^{1} \mathrm{H}$ magnetic resonance spectroscopic studies of skeletal muscle: an analytical review. Magn Reson Q 10:43-63

Mancini DM, Bolinger L, Liu H, Kendrick K, Chance B, Wilson JR (1994) Validation of near-infrared spectroscopy in humans. J Appl Physiol 77:2740-2747

Mizuno M, Secher NH, Quistorff B (1994) ${ }^{31}$ P-NMR spectroscopy, rsEMG, and histochemical fiber types of human wrist flexor muscles. J Appl Physiol 76: 531-538
Pollard V, Prough DS, DeMelo AE, Deyo DJ, Uchida T, Stoddard HF (1996) Validation in volunteers of a near-infrared spectroscope for monitoring brain oxygenation in vivo. Anesth Analg 82:269-277

Quistorff B, Johansen L, Sahlin K (1993) Absence of phosphocreatine resynthesis in human calf muscle during ischemic recovery. Biochem J 291:681-686

Rådegran G (1997) Ultrasound Doppler estimates of femoral artery blood flow during dynamic knee extensor exercise in man. $\mathrm{J}$ Appl Physiol 83:1383-1388

Richardson RS, Noyszewski EA, Kendrick KF, Leigh JS, Wagner $\mathrm{PD}$ (1995) Myoglobin $\mathrm{O}_{2}$ desaturation during exercise. Evidence of limited $\mathrm{O}_{2}$ transport. J Clin Invest 96: 1916-1926

Secher NH, Saltin B (1994) Modulation of metabolic vasodilation during dynamic exercise in man. J Exerc Sci 4:1-10

Severinghaus JW (1994) Exercise $\mathrm{O}_{2}$ transport model assuming zero cytochrome $\mathrm{PO}_{2}$ at $\mathrm{VO}_{2}$ max. J Appl Physiol 77:671-678

Stringer WK, Wasserman K, Casaburi R, Porszasz J, Maehara K, French W (1994) Lactic acidosis as a facilitator of oxyhemoglobin dissociation during exercise. J Appl Physiol 76:14621467

Taylor DJ, Bore PJ, Styles P, Gadian GD, Radda GK (1983) Bioenergetics of intact human muscle by ${ }^{31} \mathrm{P}$ nuclear magnetic resonance study. Mol Biol Med 1:77-94

Wahren J (1976) Quantitative aspects of blood flow and oxygen uptake in the human forearm during rhythmic exercise. Acta Physiol Scand 67 [Suppl 269]:51-61

Wang Z, Noyszewski E, McCully K, Ferraro N, Lanoce V, Chance B (1990) In vivo MRS measurement of deoxymyoglobin in human forearms. Magn Reson Med 14:562-567

Wilson JR, Mancini DM, McCully K, Ferraro N, Lanoce V, Chance B (1989) Noninvasive detection of skeletal muscle underperfusion with near-infrared spectroscopy in patients with heart failure. Circulation 80:1668-1674

Winters JM, Woo S (1990) Multiple muscle systems: biomechanics and movement organization. Springer, Berlin Heidelberg New York

Van der Zee P, Cope M, Arridge SR, Essenpreis M, Potter LA, Edwards AD, Wyatt JS, McCormick DC, Roth SC, Reynolds EOR, Delpy DT (1992) Experimentally measured optical pathlength for the adult head, calf and forearm, and the head of the newborn infants as a function of interoptode spacing. In: Goldstick TK (ed) Oxygen transport to tissue, vol XIII, Plenum press New York, pp:143-153 